\title{
WHAT ARE THE CURRENT OPINIONS AND PERCEPTIONS OF CLINICAL STAFF TOWARDS CARING FOR OBESE PATIENTS? KEY DEBATES AND ISSUES: A QUALITATIVE RESEARCH STUDY IN A CARDIAC CENTRE IN BAHRAIN.
}

Sandra Goodwin ${ }^{*}$, Catherine Abouzaid ${ }^{2}$,

*l MKCC Supervisor, Bahrain. ${ }^{2}$ RCSI, Lecturer in Nursing, Bahrain.

*Corresponding Author: -

\begin{abstract}
: -
This study was conducted in a Cardiac Center in Bahrain. The cessation of obesity in the country is very high (Ministry of Health, 2012) and according to the World Health Organization (nd) obesity related diseases has been the cause of concern among men and women, also related disease such as cardiovascular, diabetes and chronic respiratory diseases are rising dramatically.
\end{abstract}

Keywords: - Obesity. Cardiovascular. Educationalist. Lifestyle. Rehabilitation. Attitude. Behaviour. 


\title{
INTRODUCTION \\ Rationale for the Study
}

According to The World Health Organization (WHO), (2014) "Worldwide obesity has more than doubled since 1980, and in 2014, more than 1.9 billion adults, 18 years and older, were overweight. Of these over 600 million were obese and 39\% of adults aged 18 years and over were overweight in 2014, and 13\% were obese. Most of the world's population lives in countries where overweight and obesity kills more people than underweight and 42 million children under the age of 5 were overweight or obese in 2013". The WHO (2014) states that "Obesity is preventable".

The ontological and epistemology approach to the study will reflect the social and theoretical origins of the evidence presented. Globally obesity is both a social and economic problem. This evidence comes from statistics (WHO, 2014), that have since proved the issue to be the essence of a worldwide endemic. The ontological approach will help to understand and assess the true nature of the social world and how the world looks at obesity. As Bryman (2008) in Unit 1 Guide, Laureate, 2015, explained that the key question in ontology is the question of do social entities have an impact on the understandings of the reality? Obesity has to be looked at as being a realistic ongoing issue. The epistemological approach will look at the theory of the origins of the nature of knowledge, set the rule of validating and learning in the social world of what can be done to curb this concept and how this can help prevent otherwise preventable diseases

\section{Design Methodology}

The qualitative design methodology will take the form of an ontological/epistemological approach using phenomenology as a framework. The study will be based on a social research issue therefore ontological 'realism and idealism' will feature as the nature of the world from a social and natural context. Epistemological positions of the study will be how we as researchers will find the actual social world and the limiting of that knowledge.

\section{Ensuring Rigour}

Ensuring validity and rigour within the study can be achieved by using and understanding the quality of qualitative research and looking at this as having power in its language then using it to display a picture of the actual world we are looking at (Seale and Silvermman, 1997, p. 380). The trustworthiness of the study outcome should come from the qualitative analysis which will come together when the methodology is confirmed. Although validity and reliability in qualitative research is questionable (Laureate, 2015), the method of data collection should suit the actual study.

According to Ritchie (2013) "We are of the view that it is possible to find out about people's perceptions and interpretations both systematically and with rigour. Our approach draws on aspects of the scientific method in its more recent conceptions although adapted to suit the nature and aims of qualitative research. In this context we strive to conduct research that is well-designed and wellconducted and to generate well-founded and trustworthy evidence".

Well conducted research can prove that the reliability of the data analysis is true and valid. Reliability and validity in a research will give rigour to the study aims and outcomes along with the recommendations that come from the conclusions and recommendations. Credibility will come from the actual interviewees and how believable their perspectives are in the research study (Laureate, 2015).

\section{Ethical Approval}

Further to giving the study rigour, ethical approval is essential and sets out a number of principles on which the study is based. In their description Green and Thorogood (2014) explained that ethical principles are not absolute but may be shaped by wider cultural values that may vary across time and place.

\begin{abstract}
Methods
"Methods are the vehicles and processes used to gather the data" (Wisker, 2008, p. 67).

Qualitative methodology design was used for the project data collection and analysis. Data was collected and transcribed into a codebook. To ensure that the qualitative design was done using a 'quality' approach the author based the actual study design on facts from Flick (2007) where he explained the 'rationale' for qualitative research. When using a heuristic coding scheme for the structuring of qualitative data that may contain general theoretical concepts taken from theories and topic-orientated codes that have been drawn from everyday knowledge (Seale et al., 2007). The codes will be drawn from interviews conducted with the staff at a cardiac centre.
\end{abstract}

\section{Epistemological Aspect}

The rationale for the study is to assess the knowledge and make the necessary changes to increase the educational concepts of obesity in the staff of the cardiac centre therefore the epistemological aspect is essential and the attention to this valid claim is vital in our study (Green and Thorogood, 2014).

\section{Positionality}

Positionality in the study for myself as the main and only researcher is a significant position as I have the permission from my healthcare unit to carry out the study as it is appropriate to the success and progression of the cardiac centre. As a clinical supervisor (Goodwin) and an educationalists (Goodwin and Abou-Zaid) within the centre our position to actually start and continue the research throughout the process was manageable without interruption, unless some ethical issue arised during the research. 


\section{Research Setting}

The study was carried out in a cardiac centre in Bahrain. This centre has 70 beds with cardiac angiography and surgical facilities so the need for staff to have a good understanding of obesity in cardiovascular patients is of the highest importance and the staff needing to be educated to the highest level is vital. There is also a plan to move the centre to a newly customized built unit which will be within the next 18 months. This project will need experts to run the rehabilitation centre as this will be expanded from its present state. So the need for the rehabilitation centre to have a nutritionist and counsellor and staff who understand this issue and who can deal with obesity in patients is vital.

\section{Sampling/Recruitment}

Sampling and recruitment for the study was from the cardiac centre itself and will consist of consented doctors and nurses who are in key positions within the centre. The sampling will be by purposive sampling as this this will explicitly select the interviews who are likely to generate appropriate and useful data and will also include enough data to answer the research question (Green and Thorogood, 2014).

\section{Data Collection}

The data was collected from 3 participants from different healthcare backgrounds. Two participants were from nursing backgrounds and one was a doctor. All participants were from cardiology backgrounds as this would have an impact on the result due to the fact that they all are aware of the implications of obesity among patients, and the results would show how this impacts on their own perspectives on the disease process.

\section{Semi-Structured One-to-One Interviews}

The one-to-one semi-structured interviews were preferred to enable the researcher to capture people's opinions, feelings and practice and it would also experience the kind of atmosphere and see how they acted and responded to certain questions being asked (Wisker, 2008, p. 191). This design methodology structure was preferred by the researcher as it would help to set the real feelings and attitudes of the participant in general. Most qualitative data that has been collection strategies have some attention to the actual structure even if the researcher's intention is to follow entirely the direction taken by the participants while the researcher does not impose any structure and coverage of data collection (Ritchie and Lewis, 2005). Collecting data with some specific questions and prompts to increase awareness of the participant's answers will help them gain insight to the subject matter they are actually asking about. Open ended questions will also encourage the participant to engage in conversation rather than yes/no answers.

\section{Ethical Approval}

Ethical approval was granted by the participating organization itself and all paperwork saved into a password protected folder on my computer. Informed consent will be obtained from all participants and guidelines explained before undertaking any interview appointments and scheduling of interviews will also have approval from all participants. All appointments for the one-to-one semi-structured interviews were scheduled by email. All data will be protected on the computer by a password and all recorded interviews will be kept in a drawer with a lock and key. The published data will be anonymous and all reference to name or place will be deleted and not published. Human subjects committees and procedures are there to protect human beings (Krueger and Casey, 2009).

The participants will be asked to sign a consent form to enable the researcher to have permission to conduct interviews. The information regarding the purpose of the study will also have to be given to the participants to read and understand. Informed consent should be based on the understanding that the participation in the study is voluntary, this has to be emphasized to the participants. Ethical standards should be: respect for the individual, respect the knowledge and insight of clients, avoid practices that are unfair, be willing to explain the bases for decision making and respect privacy at all times (British Psychological Society, 2009).

"At this stage, people have consented to take part in an interview and to the researcher using data in the way described. However, consent is not absolute and needs to be assessed, and sometimes renegotiated, particularly during data collection", (Ritchie and Lewis, 2003, p. 67).

\section{Transcribing}

The data from the semi-structured interviews were recorded and transcribed verbatim onto a table which will then be coded into themes and sub-themes for analysis. This recorded data is known as

'raw' data and should be comprising of verbatim transcripts or interviews or even discussions (Ritchie and Lewis, 2007, p. 220). Transcribing the data collected was also supplemented by notes taken during the one-to-one interviews. Transcribing the recorded interviews onto the computer as a word document was seen as the best way to analyze the data. As Ritchie and Lewis (2007, p. 221) describe the process of identifying and labeling the themes as they are sorted out. The analysis will show the major issues concerned with smoking cessation and recommendations will be taken from the results.

\section{Thematic Analysis}

Using thematic analysis this brings out the most used narrative themes from the interviews. These are then categorized according to coding then split into sub-themes. The data analysis will be done by using narrative and with some graphic table content which will be the codebook. Coding will be used for the actual analysis and the results published in table 
form. A coding workbook (see figure 1) has been developed to look at the perceptions, attitudes and understanding of obesity in healthcare.

Figure 1. Codebook

\begin{tabular}{|c|c|c|}
\hline Themes /Categories & Subthemes/subcategories & Codes \\
\hline \multirow[t]{3}{*}{ understanding of obesity } & $\begin{array}{c}\text { Understanding Obesity } \\
\text { (Question 1) }\end{array}$ & $\begin{array}{c}\text { 1.1 Stigma } \\
1.2 \text { Visibly overweight. } \\
1.3 \text { Self-reflection }\end{array}$ \\
\hline & $\begin{array}{c}\text { Definition } \\
\text { (Question 1-2) }\end{array}$ & $\begin{array}{c}\text { 1.4 BMI } \\
\text { 1.5 Lack of exercise } \\
\text { 1.6 Lifestyle modification }\end{array}$ \\
\hline & causes(Questions $1 \& 3$ ) & 1.7 Bad lifestyle \\
\hline \multirow[t]{2}{*}{$\begin{array}{l}\text { Perceptions and effects of } \\
\text { obesity on health care }\end{array}$} & $\begin{array}{c}\text { Influences and Knowledge } \\
\text { (Questions 1-6) }\end{array}$ & $\begin{array}{c}\text { 2.1 Multifactorial } \\
\text { 2.2 Resulting disease } \\
\text { processes } \\
2.3 \text { Bias }\end{array}$ \\
\hline & $\begin{array}{c}\text { Body image } \\
\text { (Questions 1-4) }\end{array}$ & $\begin{array}{l}\text { 2.4 Perception size } \\
2.5 \text { Self esteem }\end{array}$ \\
\hline \multirow[t]{3}{*}{$\begin{array}{l}\text { Impact of obesity on } \\
\text { patient's health }\end{array}$} & $\begin{array}{c}\text { Diseases related to obesity } \\
\text { (Question 2-4) }\end{array}$ & $\begin{array}{l}\text { 3.4. No opinion regarding } \\
\text { obese patients }\end{array}$ \\
\hline & & $\begin{array}{l}\text { 3.5. Educating patients } \\
\text { about obesity. } \\
\text { 3.6. Epidemic of obesity. } \\
\text { 3.7 Morbidity of obesity }\end{array}$ \\
\hline & $\begin{array}{l}\text { Risk in surgery } \\
\text { (Questions 2) }\end{array}$ & $\begin{array}{c}\text { 3.8 Outcome of operation } 3.9 \\
\text { Risk in anesthesia for obese } \\
\text { patients }\end{array}$ \\
\hline \multirow[t]{3}{*}{$\begin{array}{l}\text { Practices of obesity } \\
\text { management in rehab }\end{array}$} & $\begin{array}{l}\text { Looking after obese } \\
\text { patients/pre and } \\
\text { postoperatively. } \\
\text { (Questions 2-5) }\end{array}$ & $\begin{array}{l}\text { 4.1 Code of practice of } \\
\text { nursing. } \\
\text { 4.2 Immobile patients } \\
\text { 4.3 Affects patients care } \\
\text { 4.4 Intra-professional care }\end{array}$ \\
\hline & Professions & 4.5 Ethical Issues \\
\hline & recommendations & 4.6 Lifestyle changes \\
\hline
\end{tabular}

\section{Findings}

The results from the interview questions showed the level of understanding that the nursing and medical have in dealing with obesity as a concept and as an issue in cardiovascular disease. The interview with the staff from the cardiac centre revealed that there are different views on how obesity affects patients and the disease processes.

The results included the understanding of what obesity actually and how the staff receive how it is measured.

Theme 1 was understanding of obesity and how much of a stigma it was to the patient to be overweight and how it would affect the quality of care. It also looked at how the patient felt being visibly overweight and how after treatment they could face lifestyle changes and reflect on how they could change their attitudes and behaviors. These attitudes and behaviors were a reflection on the staff answers e.g. "Obesity to me is when a patient is markedly, and visibly overweight".

Theme 2 looked at perceptions and effects of obesity on health care workers, this also included a subcategory of bias. The answer to a question in this category was "A nurse and you are a caring professional and you look after whomever you look after". The influence and knowledge that the healthcare workers have should encourage the patient to start to look at their own perception of obesity and see how the fact that they are obese is affecting the disease process and the way in which they are viewed by the cardiac staff may be altered. The patient's body image may not be that of obesity but of normality therefore the need for counselling is so important for their recovery. Their size may not be an issue. There is 
also a growing body of research that supports a view that health care providers are biased in their approach to caring for obese patients (Creel and Tillman, 2011). So evidence does exist to support this study.

Theme 3 looked at the practices of obesity management in rehabilitation of cardiac patients. They also felt that looking after obese patients who pre-operative patients may need more care is more work and the patients are more at risk. The staff have to look at their allegiance to their code of practice and care for these patients according to the code and this is for doctors and nurses alike. Ethical issues that may bring the staff to consider that these patients cause more problems cannot be considered and the law of ethics has to be maintained at all time. An example of the nurses answer is as follows, "To care for obese patients we come across these problems when you look after them, they are overweight, they can't move, they're immobile, there are lots of reasons why Nurses might not like to look after obese patients". Some of the recommendations may be simply lifestyle changes.

\section{Research Outcomes}

The outcomes from the research helped in the understanding of why healthcare workers in particular, have different perceptions regarding obesity and even although they have an understanding of the actual consequences of what obesity and what it can do to long term health outcomes, the need to be able to counsel and advise them is of great importance to the recovery phase as is the actual medical treatment.

These health care workers are advising patients what to do to change lifestyles and also how obesity can be detrimental to their health so they themselves should be able to look at this issue and get help themselves. Hospitals should be looking at cutting down on the amount of health care workers who are obese by helping them to take part in and encourage actual activity. Some

countries have implemented in their healthcare organizations policies and procedures around staff activity. Maintaining healthy weight is not only important to workers but should be a high priority for their employers given the strong effect of BMI on workers' injuries (Ǿstbye, Derment and Krause, 2007).

The rationale for the study is that the existing evidence of healthcare workers being biased towards obese patients does exist and the way in which they deal with this issue is a growing concern. In Arabic-speaking countries, especially those in higher-income, oil-producing countries including Bahrain, the prevalence of obesity in children and adolescents ranges from $5 \%$ to $14 \%$ in males and from $3 \%$ to $18 \%$ in females (Badran and Laher, 2011).

\section{Conclusion and Recommendations}

What this research suggests is that the staff of the cardiac centre although having a reliable source of knowledge on obesity and its effect on the cardiovascular system, they will also need support in teaching these patients aspects of lifestyle changes and rehabilitation.

More in-service training on being able to deal with obesity and the disease processes linked to this issue should be held as mandatory update sessions for all staff. Being able to encourage staff also to keep fit and take regular exercise as well as healthy eating habits will be part of the in-house agenda for staff development.

\section{References}

[1].Badran, M. and Laher, I. (2011) 'Obesity in Arabic-Speaking Countries', Journal of Obesity, 2011(ID 686430), doi:10.1155/2011/686430.

[2].Flick, U. (2007). Designing qualitative research. SAGE [Online]. Available

[3].from: http://srmo.sagepub.com.ezproxy.liv.ac.uk/view/designing-qualitativeresearch/SAGE.xml (Accessed: 21 February 2016).

[4].Green, J. and Thorogood, N. (2014) Qualitative Methods for Health Research. $3^{\text {rd }}$ edn. London: Sage Publications Ltd.

[5].Krueger, R., A., and Casey, M., A., (2009) Focus Groups: A Practical Guide for Applied Research, 4th edn. Thousand Oaks, California: Sage Publications Inc.

[6].Ritchie, J., and Lewis, J., (2003) Qualitative Research Practice: A Guide for Social Science Students and Researchers. London: Sage Publications Ltd.

[7].Seale, C., Gobo, G., Gubrium, G., and Silverman, D., (2007) Qualitative Research Practice. London: Sage Publications Ltd.

[8].The British Psychological Society (2009) 'Code of Ethics and Conduct', Code of Ethics Committee of the British Psychological Society, Leicester, ISBN; 978-1-85433-495-4.

[9].Wisker, G. (2008) The Postgraduate Research Handbook. $2^{\text {nd }}$ edn. New York: Palgrave MacMillan.

[10]. University of Liverpool, Laureate online Learning, Unit 1 Guide, 'The link between theoretical frameworks and the study design', Available at: http://www.laureateonlinelearning.ac.uk.com. (Accessed on: 14 January 2015).

[11]. World Health Organization, (2014) Obesity and Overweight. Available at: http://www.who.int/mediacentre/factsheets.com. Accessed on: 17 April 2016.

[12]. World Health Organization (nd) Country Cooperation Strategy: Bahrain at a glance. Available at http://www.who.int/countryfocus/cooperation_strategy/ccsbrie.com. (Accessed on: 20 January 2016). 